\title{
Study on the treatment of phenol-containing wastewater by doping coal char
}

\author{
Shuqin Wang ${ }^{1,2, *}$, Zhiqiang Zhang ${ }^{1}$, Jinghong Zhang ${ }^{1,2}$, and Xiao Zhang ${ }^{1}$ \\ ${ }^{1}$ North China Electric Power University, Department of Environmental Science and Engineering, \\ 071003 Baoding Hebei, China \\ ${ }^{2}$ North China Electric Power University, Hebei Provincial Key Laboratory of Collaborative Control \\ of Multiple Pollutants in Flue Gas of Coal-fired Power Plants, 071003 Baoding Hebei, China
}

\begin{abstract}
The single blending of biomass and $\mathrm{S}_{-} \mathrm{TiO}_{2}$ and the mixed modification of coal char were obtained by the method of coking with coal pyrolysis furnace. The adsorption performance of biomass and $\mathrm{S}^{-\mathrm{TiO}_{2}}$ was investigated by the adsorption experiment of phenol solution. The results show that under the optimal conditions the best performance of MCC-2 can achieve $94 \%$ removal efficiency of phenol.The adsorption efficiency is $20 \%$ higher than that reported in the literature, and the adsorption equilibrium time is several times shorter than that reported in the literature. The modified coal char has broad prospects as a substitute for activated carbon in practical application.
\end{abstract}

\section{Introduction}

Coal char has become a potential substitute for activated carbon due to its wide source of raw materials and low cost (about 1/3 1/10 of the market price of similar activated carbon [1]). As an adsorbent, coal char has attracted the attention of researchers due to its microporous, mesoporous structure and so on [2]. Ge XY et al. studied microwave modified coal char as adsorbent [3], and Wang Lijie et al. modified Zhongdong coal char with trace amount of $\mathrm{Ca}$ [4]. Both of them optimized the pore structure of coal char and improved the specific surface area and adsorption capacity, but failed to solve the problem of less oxygen-containing functional groups in coal char. And this is exactly the key factor affecting the application of coal char in the adsorption of phenol wastewater [5]. Therefore, the modification method which can not only increase the specific surface area of coal char, but also increase its surface functional groups, so that coal char can be used as a highly effective adsorbent for the adsorption of phenol in wastewater needs further study.

The adsorption efficiency of phenol in aqueous solution by coal char modified by biomass and titanium dioxide was studied in this paper.

* Corresponding author: wsqhg@163.com 


\section{Materials and methods}

\subsection{Chemicals}

Anhydrous ethanol (AR), tetrabutyl titanate (AR), acetic acid (AR), hydrochloric acid (AR), phenol (AR), 4-aminoantipyrine (AR), potassium ferricyanide (AR), ammonium chloride (AR), ammonia water (AR), sodium hydroxide (AR), $\mathrm{S}_{-} \mathrm{TiO}_{2}$.

\subsection{Materials}

The simulated water sample used in the experiment is composed of phenol-containing wastewater with different concentrations.

Preparation of S-TiO 2 : Taking thiourea and $\mathrm{TiO}_{2}$ as raw materials, the S-modified $\mathrm{TiO}_{2}$ with different doping ratios was prepared by hydrothermal synthesis method.

Preparation of pulverized coal and biomass powder: Four kinds of coal samples were numbered as No. 1, No. 2, No. 3 and No. 4 respectively, ground into powder by ball mill, sieve through $240 \mathrm{mesh}$, and dried for reserve use. The dried rape straw, garland chrysanthemum, wheat, cotton stalk these 4 kinds of biomass with the shredder, through 100 mesh sieve, dry reserve use.

Preparation of modified coal coke: coke is made by coal pyrolysis furnace. The biomass powder was mixed with coal powder at a ratio of $3: 7$ (the experiment requiring $\mathrm{TiO}_{2}$ modification was doped with $\mathrm{S}-\mathrm{TiO}_{2}$ at a mass ratio of $5 \%$ ).

\subsection{Characterization of adsorbents}

The specific surface area, pore size and pore volume of coal char were measured using SA3100 BET analyzer (Beckman Coulter Co., Ltd., USA). Quanta F250 SEM (FEI Company, USA) was used to observe the morphology of coal char. Phi Quantera SXM type XPS (UlvacPhi, Japan) was used to analyze the valence structure and element connection mode of coal char. The functional groups of coal char were analyzed by Nicolet IS5 FT-IR (Thermo Fisher Company, USA).

\subsection{Experiments}

At room temperature, 200mg/L phenol solution was adjusted with $\mathrm{HCl}$ or $\mathrm{NaOH}$ to the $\mathrm{pH}$ required by the experiment. For each experiment, $100 \mathrm{~mL}$ of coal coke and the designed amount were mixed into a conical flask. The conical flask containing the mixed solution was placed in a thermostatic oscillator with a speed of $150 \mathrm{r} / \mathrm{min}$ for reaction for a period of time and then taken out. Take a certain amount of solution after filtration with "HJ 5032009 water quality determination of volatile phenol 4-Amino Antipyriline photometric method" to measure the concentration of residual phenol after adsorption.

\section{Results and discussion}

Table 1. Adsorption efficiency under different conditions.

\begin{tabular}{ccccccccc}
\hline $\begin{array}{c}\mathrm{pH} \\
\text { Value }\end{array}$ & $\begin{array}{c}\text { Reduction } \\
\text { Efficiency } \\
(\mathrm{CC}, \%)\end{array}$ & $\begin{array}{c}\text { Reduction } \\
\text { Efficiency } \\
(\mathrm{MCC}-\end{array}$ & $\begin{array}{c}\text { Dosage } \\
(\%)\end{array}$ & $\begin{array}{c}\text { Reduction } \\
\text { Efficiency } \\
(\mathrm{MCC}-\end{array}$ & $\begin{array}{c}\text { Reduction } \\
\text { Efficiency } \\
(\mathrm{MCC}-\end{array}$ & $\begin{array}{c}\text { Initial } \\
\text { Conten } \\
(\mathrm{mg} / \mathrm{L})\end{array}$ & $\begin{array}{c}\text { Reduction } \\
\text { Efficiency } \\
(\mathrm{MCC}- \\
1, \%)\end{array}$ & $\begin{array}{c}\text { Reduction } \\
\text { Efficiency } \\
(\mathrm{MCC}-\end{array}$ \\
\hline 1 & 85 & 24 & 0 & 80 & 80 & 200 & 78 & 94 \\
\hline
\end{tabular}




\begin{tabular}{lllllllll}
\hline 2 & 84 & 23 & 1 & 87 & 83 & 400 & 55 & 80 \\
4 & 81 & 21 & 3 & 93 & 85 & 600 & 50 & 65 \\
6 & 76 & 19 & 5 & 94 & 88 & 800 & 39 & 54 \\
8 & 70 & 22 & 7 & 90 & 82 & 1000 & 35 & 47 \\
\hline
\end{tabular}

\subsection{Effect of pH on adsorption efficiency of coal char}

According to the method shown in 2.4, after several experiments, the optimal dosage of coal char is $4 \mathrm{~g} / \mathrm{L}$, the optimal $\mathrm{pH}$ is 1 , the optimal coking temperature is $850^{\circ} \mathrm{C}$, and the optimal modified biomass is rapeseed straw. The equilibrium of the adsorption reaction can be reached in $30 \mathrm{~min}$, which is several times shorter than the adsorption time of phenol in activated carbon adsorption solution for 3.5h[6] and 6h[7] reported in literature. The adsorption experiment results of different variables under the optimal conditions are shown in Table 1, in which CC refers to undoped raw coal char, MCC-1 refers to rape straw single doped coal char, MCC-2 refers to rape straw and $\mathrm{S}_{-} \mathrm{TiO}_{2}$ co-doped coal char, and MCC-3 refers to $\mathrm{TiO}_{2}$ single doped coal char. It can be seen from Table 1 that $\mathrm{pH}$ changes have a great impact on the adsorption efficiency, and the adsorption efficiency of coal char modified by rape straw with the best performance in the whole $\mathrm{pH}$ gradient decreases by $30 \%$. The adsorption efficiency of coal char is the highest when $\mathrm{pH}=1$, and the adsorption efficiency of all kinds of coal char on phenol decreases with the increase of $\mathrm{pH}$ of the solution, which is the same as the research results reported in literature [6,8]. Some studies [9] believe that the change of solution $\mathrm{pH}$ affects the surface charge of coke adsorbent and the dissociation and protonation of adsorbent, thus affecting the adsorption efficiency [10]. What is commendable is that the adsorption efficiency of MCC-1 is still about $70 \%$ under weakly alkaline conditions.

\subsection{Effect of $\mathrm{TiO}_{2}$ on adsorption efficiency before and after modification}

Ten kinds of codoped modified coal char were prepared by doping $\mathrm{TiO}_{2}$ and $\mathrm{S}-\mathrm{TiO}_{2}$ at different mass ratios of $1 \%, 3 \%, 5 \%, 7 \%$ and $9 \%$, respectively. As can be seen from Table 1 , the adsorption efficiency of coal char increases first and then decreases with the increase of doping ratio for both pure $\mathrm{TiO}_{2}$ and $\mathrm{S}_{-} \mathrm{TiO}_{2}$. When $5 \% \mathrm{~S}_{-}-\mathrm{TiO}_{2}$ is added, the adsorption efficiency is the highest, reaching $93 \%$. This is 1.4 times of the adsorption efficiency of volatile phenol from coking wastewater by activated sludge activated carbon as reported in literature [11], and about $20 \%$ higher than that by ammonia modified activated carbon [7] and grapefruit peel biochar [8].

\subsection{Effect of initial concentration on adsorption efficiency of coal char}

It can be seen from the table that the concentration of initial pollutants has a great influence on the adsorption efficiency of coal char. This is because the pollutants with a high concentration are clustered on the surface of the adsorbent [13], which hinders the deeper contact between the adsorbent and coal char. This result is similar to the results of the study on graphene/chitosan adsorbent in literature [14]. Modified coal char has a good treatment effect on low concentration wastewater, and the treatment efficiency of relatively high concentration wastewater around $600 \mathrm{mg} / \mathrm{L}$ is about $70 \%$, which is much higher than the treatment efficiency of the high concentration phenol-containing wastewater reported in the literature [15] by the high gravity and electrocatalytic coupling method. The comparison before and after $\mathrm{S}-\mathrm{TiO}_{2}$ doping at different concentrations in the figure also indicates that $\mathrm{S}-\mathrm{TiO}_{2}$ doping can improve the adsorption performance of coal char. 


\subsection{SEM characterization}

Figure 1 is the SEM diagram of 200,000 times coal coke. It can be seen from Figure (a) that the local texture of coal char before modification is flat and smooth, and the overall structure is layered stacked, which corresponds to the layered pore structure shown by the adsorption/desorption isotherm. Figures (b) and (c) show that after modification, the layered structure of coal char is more obvious, the surface is more delicate, and there are more lumpy biomass and spherical titanium dioxide bulges. This structure provides more sites for the adsorption of phenol.
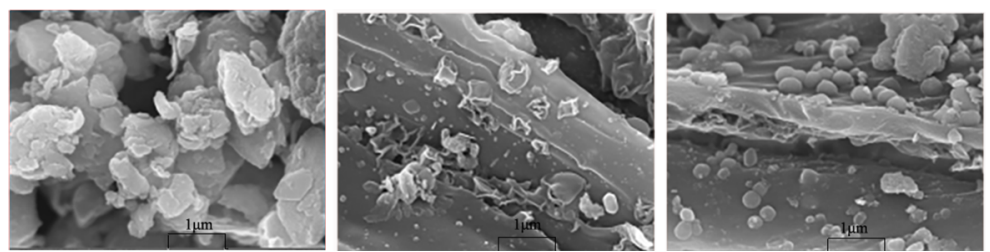

Fig. 1. SEM diagram of coal char(a,b,c from left to right).


Fig. 2. XPS diagram of coal char.

Fig. 3. Infrared spectroscopy of biomass.

\subsection{XPS characterization}

Figure 2 is the O1s peak diagram of coal char characterized by XPS. It can be seen from the figure that the main bond of oxygen element is $\mathrm{C}-\mathrm{O}$ bond $(532.4 \mathrm{eV})$ and $\mathrm{C}=\mathrm{O}$ bond $(531.2 \mathrm{eV})$. The $\mathrm{C}-\mathrm{O}$ peak area significantly increases after the modification of rapeseed straw, but the peak has no significant change after the re-doping of $\mathrm{S}_{-} \mathrm{TiO}_{2}$, which indicates that the oxygen-containing functional groups in coal char increase after the modification of biomass, and the adsorption effect of phenol is optimized. This conclusion is consistent with the experimental results of adsorption properties and the research results reported in the literature [5].

\subsection{FT-IR}

Figure 3 is the infrared spectrum of three kinds of modified biomasses used in this paper. In the figure, the peak at $3400 \mathrm{~cm}^{-1}$ is generated by associative alcohol hydroxyl or phenolic hydroxyl, and the presence of phenols and alcohols can be determined by combining the peaks at $1500 \mathrm{~cm}^{-1}$ and $1060 \mathrm{~cm}^{-1}$. The peak at $1742 \mathrm{~cm}^{-1}$ is fatty ester, the peak at $1620 \mathrm{~cm}^{-1}$ is generated by the skeleton vibration of quinoline, the peak at $1240 \mathrm{~cm}^{-1}$ represents the inplane vibration of aromatic ring, and the two small peaks between $1050-1240 \mathrm{~cm}^{-1}$ are 
ethers. Infrared spectra showed that there were abundant oxygen-containing functional groups in the three kinds of biomass, and the types were almost the same. Literature studies [16] show that biomass with high cellulose and lignin content has a better adsorption effect for coking, and biomass can be widely selected for the mixed firing modification of coal and coke in practical application.

\section{Adsorption mechanism}

\subsection{Adsorption kinetics model}

Kinetic adsorption experiments were carried out on $\mathrm{CC}, \mathrm{MCC}-1$ and $\mathrm{MCC}-2$, and Origin 2018 software was used to fit the adsorption data of three kinds of coal char according to the quasi-first-order kinetic model, the quasi-second-order kinetic model [18] and the Weber-Morris internal diffusion model. The results show that the quasi-second-order kinetic model has the best fitting effect $\left(\mathrm{R}^{2}\right.$ of the three kinds of coal char is $0.941,0.997,0.999$, respectively), which indicates that the adsorption process is mainly chemisorption. The fitting correlation of the internal diffusion model is low, indicating that the adsorption process is not a single internal diffusion control. The adsorption rate constants $\mathrm{k} 1$ and $\mathrm{k} 2$ of coal char increased after modification, which indicated that the modification accelerated the adsorption reaction rate of coal char.

\subsection{Adsorption isotherm model}

Origin 2018 was used to fit the adsorption data of MCC-2 at three temperatures of $298 \mathrm{~K}$, $308 \mathrm{~K}$ and $318 \mathrm{~K}$, and the results showed that Langmuir model $\left(\mathrm{R}^{2}\right.$ is $0.999,0.998,0.996$, respectively) and Temkin model ( $\mathrm{R}^{2}$ is $0.986,0.972,0.961$, respectively) had a high fitting correlation. The adsorption constants of $\mathrm{B}_{\mathrm{T}}$ in Temkin model are all less than $1 \mathrm{~kJ} / \mathrm{mol}$, indicating that the adsorption reaction is endothermic. In this paper, it is speculated that the reason why the Langmuir model can be well fitted is that the modified coal char surface functional groups play a major role in adsorption, and these homogeneous functional groups are like a layer of coating to homogenize the coal char surface.

\section{Conclusion}

The modified coal char MCC-2 with the best adsorption performance was screened out through experiments. After modification, the equilibrium adsorption quantity of the modified coal char was 4.5 times of the original, and the adsorption efficiency of phenol under acidic conditions was $93 \%$. In the similar adsorbents reported in other literatures [910], the adsorption efficiency of MCC- 2 was also about $70 \%$ under weak alkaline conditions with poor performance and at a higher concentration of $600 \mathrm{mg} / \mathrm{L}$. The adsorption of phenol by modified coal char conforms to the quasi-second-order kinetic model and Langmuir isothermal adsorption model, and the adsorption process is mainly chemisorption. The adsorption reaction can reach equilibrium within $30 \mathrm{~min}$, which is several times shorter than the adsorption time reported in the literature [10,14]. As a cheap substitute for activated carbon, it has a broad prospect in practical application.

This work was financially supported by Fundamental Research Funds for the Central Universities (No. 2017 MS136) 


\section{References}

1. Z. Mengqi, H. Yuxing, X. Chunyan, et al. Science of the Total Environment 653, 64-73 (2004)

2. W. Liyuan, D. Chunxiao, H. Juan, et al. Journal of Hazardous Materials 384 (2020)

3. G. Xinyu, F. Tian, W. Zhilin, et al. Science of the Total Environment 91, 67-77 (2015)

4. W. Lijie, S. Fei, P. Xinxin, et al. Journal of Engineering Thermophysics 39, 2559-2567 (2018)

5. W. Qiongjie, Z. Yong, W. Jinxiaoxue, et al. Technology of Water Treatment 46, 7-11 (2020)

6. G. Lili, L. Hairui, Z. Hongxi. Shandong Chemical Industry 45, 182-185 (2016)

7. D. Chunsheng, N. Fangming, M. Jia, et al. Journal of Wuhan University of Technology 35, 1237-1241 (2011)

8. W. Shengwan, H. Xiaoyan, J. Dao, et al. Chemical Industry and Engineering Progress 639, 352-361 (2020)

9. H. Qiuxiang, C. Zuliang. Chinese Journal of Environmental Engineering 8, 3853-3859 (2014)

10. L. Yunchao, H. Haotao, Z. Dazhou, et al. Chemical Industry and Engineering Progress 35, 225-231 (2016)

11. X. Wanting, Y. Yaoseng, T. Moucheng, et al. Industrial Water Treatment 40, 87-90 (2020)

12. L. Yali, L. Xin, J. Zhaoqiang, et al. Industrial Water Treatment 39, 25-28 (2019)

13. Z. Jinghong, W. Shuqing, L. Lifeng, et al. Journal of the Chinese Ceramic Society 647 , 1441-1449 (2019)

14. S. Ming, W. Anwei, H. Hui, et al. Industrial Water Treatment 39, 17-21 (2019)

15. L. Yingdi, L. Youzhi, G. Jing, et al. Chemical Industry and Engineering Progress 34, 2070-2074 (2015)

16. W. Chongqing, W. Hui, J. Xiaoyan, et al. Chemical Industry and Engineering Progress 38, 692-706 (2019)

17. E. Y1lmaz, E. Sert, F. S. Atalay. Journal of the Taiwan Institute of Chemical Engineers 65, 323-330 (2016) 